GASTRIC CANCER

\title{
Chromoendoscopic surveillance in hereditary diffuse gastric cancer: an alternative to prophylactic gastrectomy?
}

\author{
D Shaw, V Blair, A Framp, P Harawira, M Mcleod, P Guilford, S Parry, A Charlton, I Martin
}

Gut 2005;54:461-468. doi: 10.1136/gut.2004.049171

Background: Hereditary diffuse gastric cancer (HDGC) is defined by germline mutations in the E-cadherin gene, $C D H-1$. The first family in which $C D H-1$ mutations were identified was a large Maori kindred, where lifetime penetrance is $70 \%$. Prophylactic gastrectomy is an unacceptable option for many mutation carriers. The results of annual chromoendoscopic surveillance using the methylene blue/congo red technique in 33 mutation carriers over a five year period are described.

Patients and methods: Thirty three confirmed $\mathrm{CDH}-1$ mutation carriers (18 males, 15 females), median age 32 years (range 14-69), were enrolled in 1999-2003. Medical records, endoscopy, and pathology were reviewed retrospectively.

See end of article for authors' affiliations

Results: Over five years, 99 surveillance endoscopies were performed, of which 93 were chromo-dye enhanced. Sixty nine chromoendoscopies were normal. In 24 procedures, 1-6 pale areas/stomach (size 2-10 mm) were detected post chromo-dye application (totalling 56 pale lesions). One biopsy was taken from each pale lesion: 23 lesions (41\%) showed signet ring cell carcinoma (10 patients), 10 lesions (18\%) gastritis (four patients), and $23(41 \%)$ normal mucosa (10 patients). No chromo-dyes were used in six procedures with macroscopic lesions (two HDGC, four ulceration). Total gastrectomies from patients with carcinoma were macroscopically normal but pathological mapping showed multiple microscopic foci of early signet ring cell carcinoma. Correlation of chromoendoscopic and gastrectomy findings showed that congo red/methylene blue detected carcinoma foci $4-10 \mathrm{~mm}$ in size but not foci $<4 \mathrm{~mm}$.

Correspondence to: Dr D Shaw, Tauranga Hospital, Private Bag 12 024, Tauranga, New Zealand; David.Shaw@ bopdhb.govt.nz

Revised version received 14 August 2004 Accepted for publication 11 September 2004

Conclusions: The use of chromoendoscopy following normal white light gastroscopy facilitated detection of early gastric carcinoma foci not visible with white light gastroscopy. If these findings are validated in other HDGC kindred, chromogastroscopy represents an improved surveillance technique that can be safely considered alongside prophylactic gastrectomy.

1 1964, Jones described an extended multigenerational New Zealand Maori family with a high incidence of gastric cancer and speculated on an underlying genetic cause. This speculation was proved correct in 1998 with the identification of inactivating germline mutations in the gene for the cell to cell adhesion protein E-cadherin $(C D H-1)$ in this family (family A) and two other unrelated Maori diffuse gastric cancer kindred. ${ }^{2}$ Subsequently, germline $C D H-1$ mutations have been observed in gastric cancer families of diverse ethnic origins and a new familial cancer syndrome defined, called hereditary diffuse gastric cancer (HDGC). ${ }^{3}$ Of families meeting minimal clinical criteria, ${ }^{4} 30 \%$ have been found to have $C D H-1$ mutations and worldwide over 40 HDGC families have now been identified (P Guilford, personal communication).

Predispositional genetic testing for the E-cadherin germline mutation first became available to members of family A in 1998 and since then 33 family members have been identified as carriers of the mutation. Family members undergoing regular white light endoscopic surveillance who were subsequently identified as not carrying the $C D H-1$ mutation were advised that this could be safely discontinued. The management options available to the $C D H-1$ mutation carriers posed a number of difficult issues, requiring assessment of the relative risks and benefits of prophylactic gastrectomy versus gastroscopic surveillance. This involves consideration of the natural history and penetrance in HDGC, in addition to the risks of prophylactic gastrectomy and the diagnostic limitations of standard endoscopy. Individual patient circumstances, cultural factors, and ethical issues relating to gaps in understanding of the natural history of HDGC also influence management strategies.
The lifetime penetrance of HDGC in family A is $70 \%{ }^{2}$ The 26 family members who died from gastric cancer between 1962 and 1999 had a median age at diagnosis of 33 years (range 14-74). Some family members in other HDGC case series have decided against prophylactic surgery. ${ }^{4}$ In light of the morbidity (anastomotic leak 8-12\%; wound/intraabdominal sepsis 5-10\%; oesophageal stricture 10-15\%), mortality (30 day 3-6\%), and long term consequences (100\%: dumping syndrome, diarrhoea, and weight loss) of total gastrectomy, Lewis et al commented that prophylactic gastrectomy represents a new level of risk for patients with genetically defined disease. ${ }^{6}$ The increased risk of malabsorption after total gastrectomy (vitamin D, calcium, folate, and iron) and consequently osteoporosis, osteomalacia, and malnutrition are well described in gastric cancer patients, usually aged 60-70 years, ${ }^{7}$ but there are few data in younger patients.

Endoscopic surveillance, while having the obvious benefit of stomach preservation, has the risks of incomplete patient compliance and imperfect sensitivity. The diagnostic limitations of standard white light endoscopy motivated a review of methods that enhance the clinician's ability to detect early gastric cancer (DS). New techniques such as fluorescent technology and confocal microscopy remain experimental. ${ }^{8}$ Chromoendoscopy however is relatively straightforward and employs dyes that are inexpensive and accessible. Contrast agents (for example, indigo carmine) which enhance mucosal irregularities ${ }^{9}$ theoretically would have limitations in the detection of HDGC foci as diffuse gastric cancer often

Abbreviations: HDGC, hereditary diffuse gastric cancer; SRC, signet ring cell 

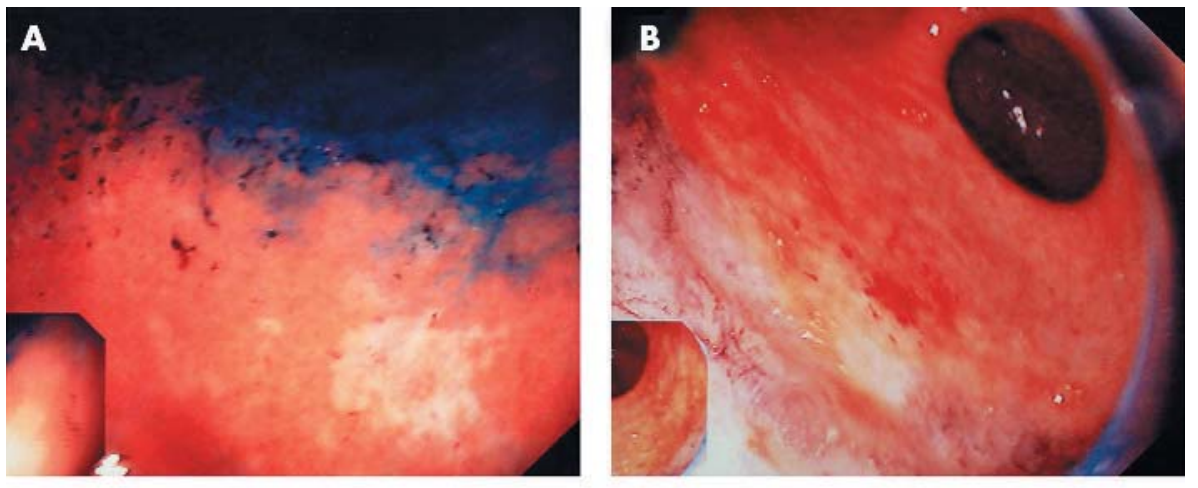

Figure 1 Pale lesions detected after congo red-methylene blue chromoendoscopy in patients with hereditary diffuse gastric cancer (HDGC). (A) A $10 \mathrm{~mm}$ pale area from case $A$ demonstrating features of a high suspicion lesion: well defined margins and distinct pallor; biopsy signet ring cell (SRC) carcinoma. (B) An $8 \mathrm{~mm}$ high suspicion pale lesion from case $B$ at the body/antrum junction on the greater curve towards the anterior wall; biopsy SRC carcinoma (magnifying endoscope image). (C) Two pale lesions at the transitional zone on the greater curve from case C; large arrow is $5 \mathrm{~mm}$ high suspicion lesion, small arrow is $3 \mathrm{~mm}$
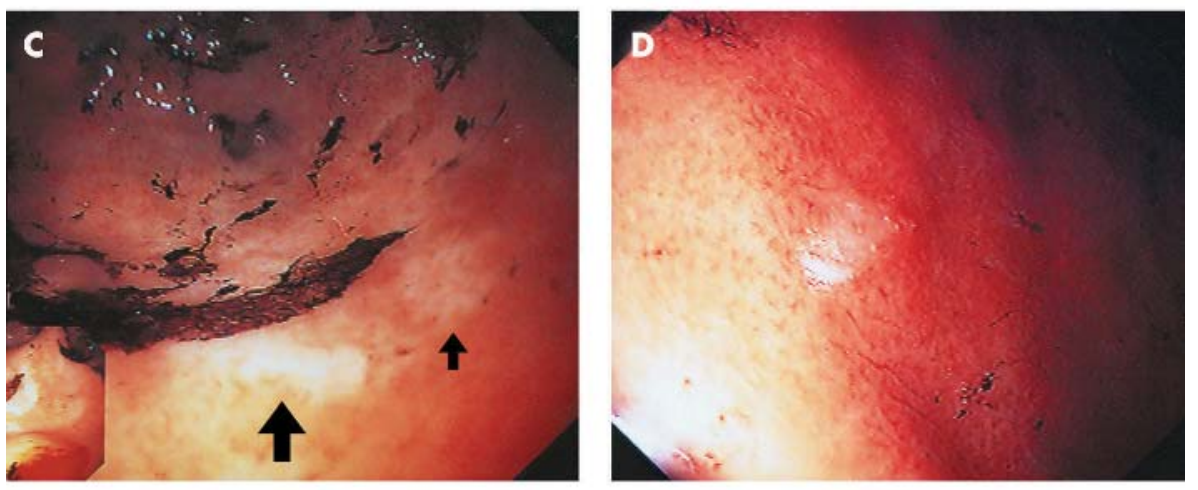
low suspicion area; both biopsies SRC carcinoma. (D) A $3 \mathrm{~mm}$ low suspicion lesion from case J; biopsy normal mucosa. (E, F) A $3 \mathrm{~mm}$ low suspicion pale area in case $G$; biopsy SRC carcinoma. Forceps image illustrates the relative size of the lesion.
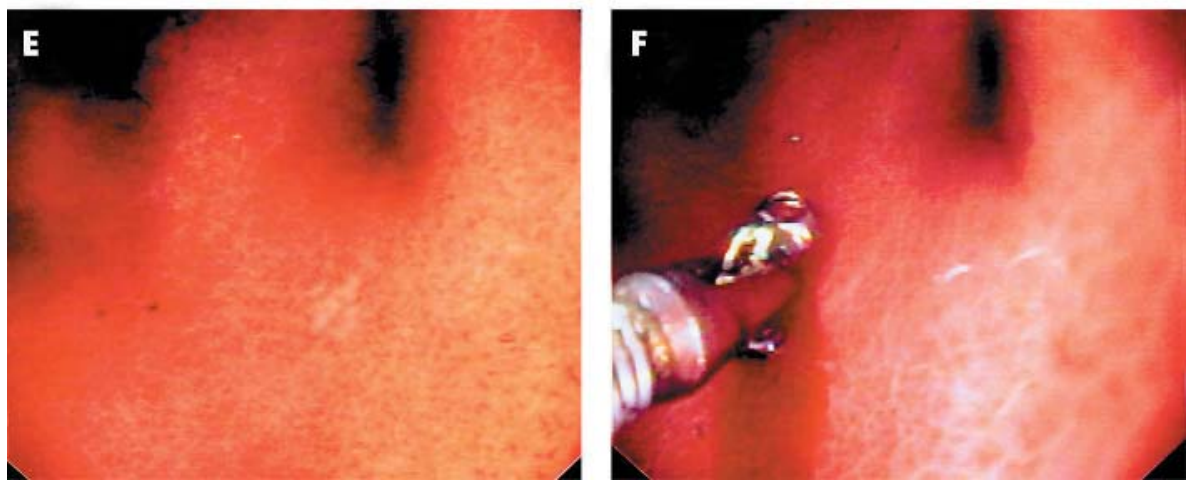

lies beneath morphologically normal mucosa with a regular crypt pattern. ${ }^{10}$

The congo red-methylene blue test was described as a method of detecting gastric cancer in Japan in 1982. ${ }^{11}$ It combines the $\mathrm{pH}$ reactive agent congo red $^{12}$ and the absorptive agent methylene blue. ${ }^{13}$ Based on the Japanese experience, this technique was employed in an attempt to enhance early gastric cancer detection in HDGC. There are no randomised controlled trials comparing this method with standard gastroscopy as a screening tool. Patients were advised of this and also that an unquantifiable risk existed that chromoendoscopy and/or standard light endoscopy may fail to detect gastric cancer.

\section{PATIENTS AND METHODS}

Family A's pedigree and their $1008 \mathrm{G} \rightarrow \mathrm{T}$ truncating germline $C D H-1$ mutation have been described previously. ${ }^{2}$ After mandatory pre and post-test counselling, $33 \mathrm{CDH}-1$ mutation carriers (18 males, 15 females) enrolled in endoscopic surveillance. Median age was 32 years (range 14-69). In the first year of surveillance, 20 patients enrolled, with 3, 3, 3, and 4 new enrolments in each subsequent year. Patient records were reviewed from 1999 to 2003. Gastrectomy specimens from patients referred for total gastrectomy (D2) contributed to a detailed pathological mapping study ${ }^{14}$ and the results were correlated with respective chromoendoscopic findings.

\section{Chromoendoscopic method}

The congo red-methylene blue method used is based on that developed by Tatsuta and colleagues. ${ }^{11}$ An alternative gastric mucolytic agent, N-acetylcysteine (Parvolex), is used. ${ }^{15}$ A single endoscopist (DS) performed all gastroscopies. Patients were fasted as per routine upper gastrointestinal endoscopy and informed consent was obtained. Thirty minutes before the procedure the patient drank a $50 \mathrm{ml}$ solution containing $2 \mathrm{~g}$ of $\mathrm{N}$-acetylcysteine(Parlovex) in $20 \mathrm{ml}$ of normal saline and $30 \mathrm{ml}$ of tap water. The patient changed position every five minutes: right side, back, and left side (two rotations: head up, head down) to facilitate complete gastric mucosal coverage by the mucolytic. Under conscious sedation, every procedure began with meticulous white light gastroscopy. Gastroduodenal ulceration is a contraindication to stimulation of gastric acid secretion using pentagastrin and thus chromostaining was rescheduled when ulceration was present. In the absence of ulceration, intravenous pentagastrin was given at $5 \mu \mathrm{g} / \mathrm{kg}$ in $10 \mathrm{ml}$ of normal saline. A spray catheter (Olympus, Tokyo, Japan) was used to firstly spray 

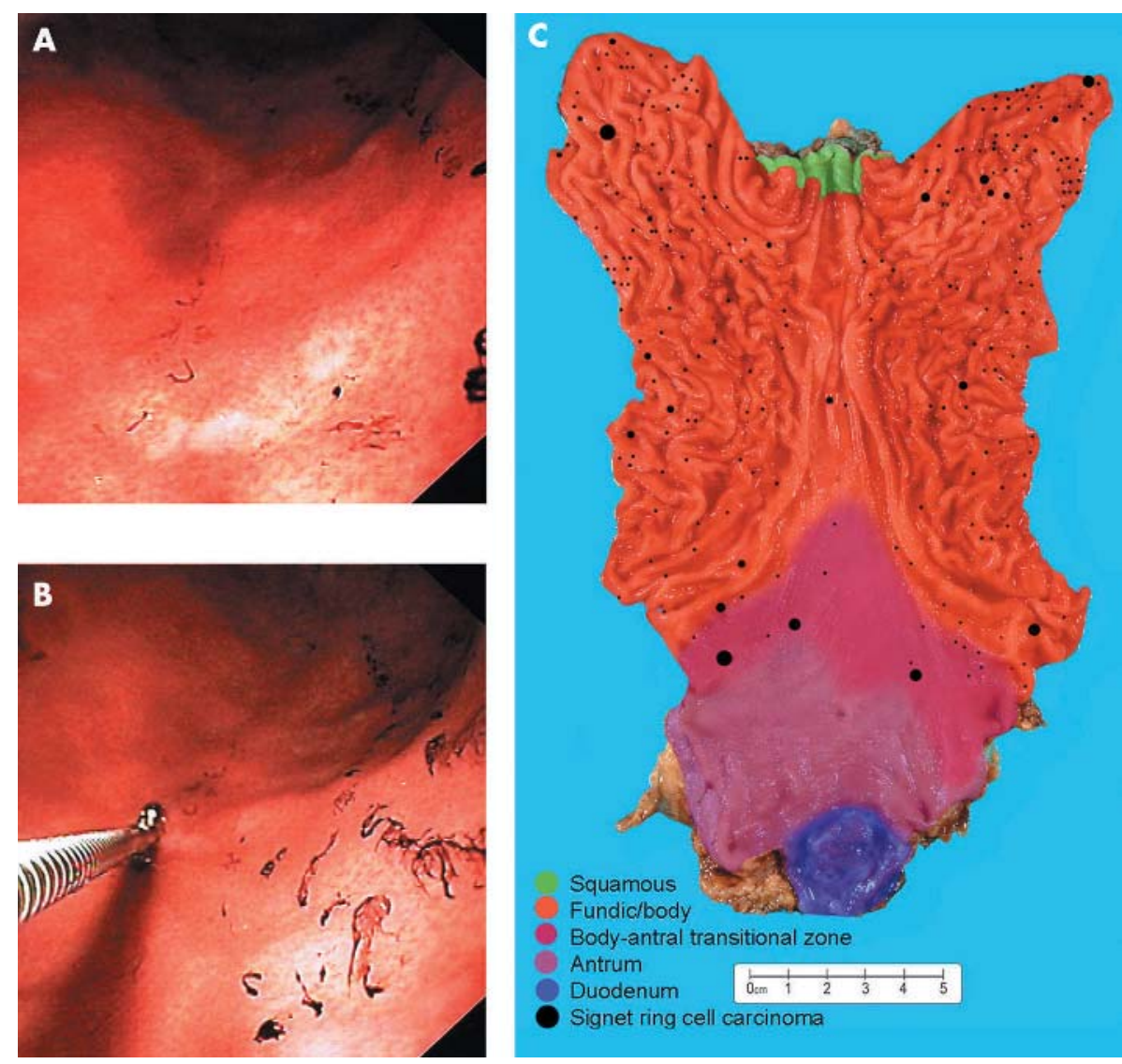

Figure 2 Case H. (A) Two $5 \mathrm{~mm}$ pale lesions both high suspicion for signet ring cell (SRC) carcinoma. (B) One biopsy taken from each lesion: both SRC carcinoma. (C) Gastrectomy mapping study with case $\mathrm{H}$ showing 238 microscopic foci of SRC carcinoma shown as black dots to scale with mucosal zones shaded as per legend (see methods ${ }^{13}$ ). The largest six foci were $3-4 \mathrm{~mm}$ in size, four of which were located in the region where pale lesions were detected by chromoendoscopy.

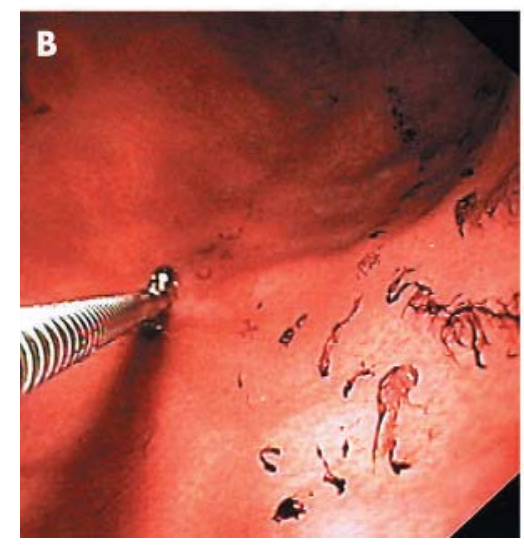

Squamous

\section{chromoendoscopy.}

methylene blue (solution of $15 \mathrm{ml}$ of $1 \%$ methylene blue with $20 \mathrm{ml}$ sterile water) over the whole gastric mucosa, allowing five minutes for mucosal absorption before residual methylene blue was suctioned away. Congo red was then applied using the spray catheter (solution of $12 \mathrm{ml}$ of $0.5 \%$ congo red, $8 \mathrm{ml}$ sterile water, and one $0.84 \mathrm{~g} / 10 \mathrm{ml}$ ampule of sodium bicarbonate). The mucosa was irrigated with water to wash away excess dye and suctioning was repeated. The gastric mucosa was subsequently observed for a minimum of 10 minutes to look for pale areas suggestive of early gastric cancer.

No random biopsies were taken. Biopsies were taken (Boston Scientific forceps; Boston Scientific, Natick, Massachusetts, USA) if: (1) macroscopic abnormalities were visible on standard white light endoscopy before dye application; (2) pale mucosal areas were detected after chromo-dye application, henceforth referred to as chromo directed biopsies; and (3) screening for Helicobacter pylori infection (first surveillance gastroscopy only). The latter were correlated with results from $H$ pylori serology which was part of another study (unpublished).

The diameter of each pale area was measured by approximation to the size of the open biopsy forceps $(5 \mathrm{~mm})$. Pale areas are described as "high" or "low" suspicion for early gastric cancer. A high suspicion lesion is characterised by clearly defined margins and is distinctly pale/white (fig $1 \mathrm{~A}-\mathrm{C}$, fig 2). In contrast, a low suspicion lesion has ill defined margins and a less distinct pallor (fig 1D, E).

The location of lesions was described with respect to the four parts of the stomach (cardia, fundus, body, and antrum) and cross sectional circumference. By dividing the circumference into four equal parts, location was either the lesser or greater curve, or anterior or posterior wall. ${ }^{16}$ The body-antrum

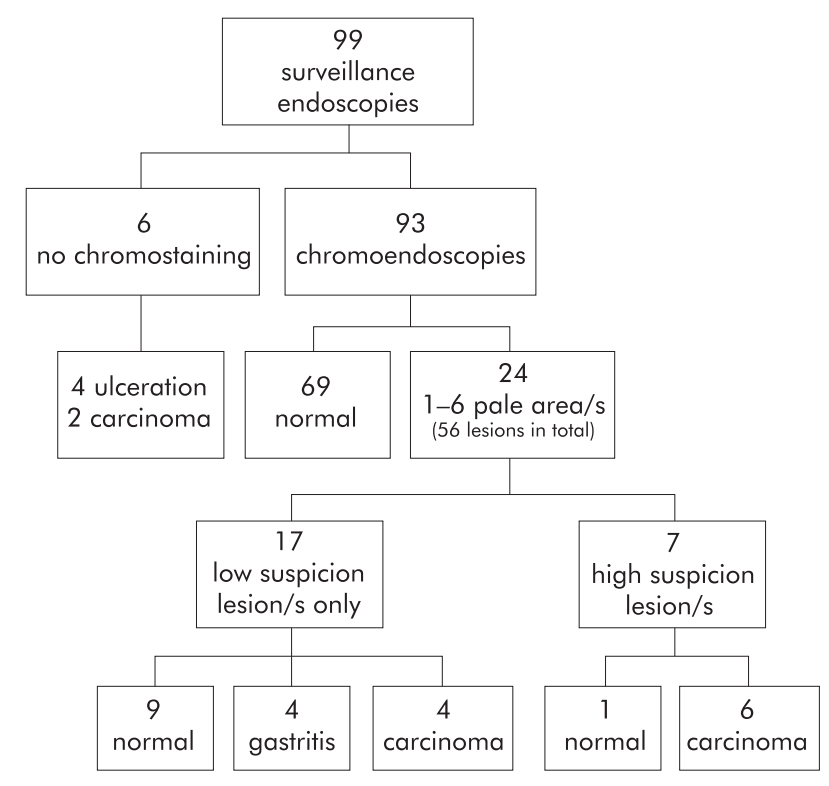

Figure 3 Outcome of 99 chromoendoscopies: five years' annual surveillance in $33 \mathrm{E}$-cadherin mutation carriers.

junction was defined anatomically by the angular notch (incisura angularis). When congo red staining resulted in clear demarcation of the transition between the acid secreting body mucosa and the non-acid secreting antral mucosa, the location descriptor "transitional zone" was also used.

An endoscopic surveillance interval of 12 months was chosen. If a patient developed upper gastrointestinal symptoms during the interval, they were clinically assessed and 
Table 1 Characteristics of chromoendoscopically identified lesions and correlation of chromoendoscopic and gastrectomy findings in patients with signet ring cell carcinoma detected on chromoendoscopic biopsy

\begin{tabular}{|c|c|c|c|c|c|c|c|c|c|}
\hline \multirow[b]{2}{*}{ Case } & \multirow[b]{2}{*}{$\begin{array}{l}\text { Age } \\
\text { sex }\end{array}$} & \multicolumn{2}{|c|}{ Index chromoendoscopy* } & \multicolumn{3}{|c|}{ Previous chromoendoscopies and pale lesions } & \multicolumn{3}{|c|}{ Gastrectomy findingsł } \\
\hline & & $\begin{array}{l}\text { Pale lesions } \mathrm{H} / \mathrm{L}+\text { : } \\
\text { size }(\mathrm{mm})\end{array}$ & Biopsy result & $\begin{array}{l}\text { Previous } \\
\text { scopes }\end{array}$ & $\begin{array}{l}\text { Pale lesions } \mathrm{H} / \mathrm{L} \dagger \text { : } \\
\text { size }(\mathrm{mm})\end{array}$ & Biopsy result & Total foci & $\begin{array}{l}\text { Foci } \\
<\mathbf{4 m m}\end{array}$ & $\begin{array}{l}\text { Foci } \\
4-10 \mathrm{~mm}\end{array}$ \\
\hline A & $39 \mathrm{M}$ & $\begin{array}{l}\text { H } 10 \\
L<3\end{array}$ & $\begin{array}{l}\text { Carcinoma } \\
\text { Normal }\end{array}$ & 1 & HNS & Normal & 45 & 40 & 5 \\
\hline B & $28 M$ & $\begin{array}{l}\text { H } 8 \\
L<3\end{array}$ & $\begin{array}{l}\text { Carcinoma } \\
\text { Normal }\end{array}$ & 2 & & & 214 & 212 & 2 \\
\hline C & $15 \mathrm{~F}$ & $\begin{array}{l}\text { H } 3 \\
\text { H } 3 \\
\text { L } 3 \\
\text { L } 3 \\
\text { L } 3\end{array}$ & $\begin{array}{l}\text { Carcinoma } \\
\text { Carcinoma } \\
\text { Carcinoma } \\
\text { Carcinoma } \\
\text { Normal }\end{array}$ & 1 & & & 318 & 311 & 7 \\
\hline $\begin{array}{l}D \\
E\end{array}$ & $\begin{array}{l}34 \mathrm{~F} \\
16 \mathrm{M}\end{array}$ & $\begin{array}{l}\mathrm{L} 3 \\
\mathrm{~L} 3\end{array}$ & $\begin{array}{l}\text { Carcinoma } \\
\text { Carcinoma }\end{array}$ & $\stackrel{4}{\mathrm{Nil}}$ & & & $\begin{array}{r}111 \\
15\end{array}$ & $\begin{array}{l}110 \\
15\end{array}$ & ${ }_{\text {Nil }}^{1}$ \\
\hline $\mathrm{F}$ & $45 \mathrm{~F}$ & $\begin{array}{l}\text { H } 3 \\
\text { H } 3 \\
L<3 \\
L<3 \\
L<3\end{array}$ & $\begin{array}{l}\text { Carcinoma } \\
\text { Carcinoma } \\
\text { Carcinoma } \\
\text { Carcinoma } \\
\text { Carcinoma }\end{array}$ & 4 & & & Gastric mo & oping penc & \\
\hline G & $27 \mathrm{~F}$ & $\begin{array}{l}\text { L } 3 \\
\text { L } 3\end{array}$ & $\begin{array}{l}\text { Carcinoma } \\
\text { Normal }\end{array}$ & 4 & & & Mapping $\mathrm{F}$ & ending & \\
\hline $\mathrm{H}$ & $20 \mathrm{~F}$ & $\begin{array}{l}\text { H } 5 \\
\text { H } 5 \\
\text { L } 3 \\
\text { L } 3 \\
\text { L } 3 \\
L<3\end{array}$ & $\begin{array}{l}\text { Carcinoma } \\
\text { Carcinoma, } \\
\text { Carcinoma } \\
\text { Carcinoma } \\
\text { Carcinoma } \\
\text { Normal }\end{array}$ & 1 & $\begin{array}{l}\text { L } 3 \\
\text { L } 3\end{array}$ & $\begin{array}{l}\text { Normal } \\
\text { Normal }\end{array}$ & 238 & 236 & 2 \\
\hline 1 & $19 M$ & $\begin{array}{l}\text { H } 5 \\
\text { H } 5 \\
\text { L } 3 \\
\text { L } 3 \\
\text { L } 3 \\
\text { L } 3\end{array}$ & $\begin{array}{l}\text { Carcinoma } \\
\text { Carcinoma } \\
\text { Carcinoma } \\
\text { Normal } \\
\text { Normal } \\
\text { Normal }\end{array}$ & 1 & $\begin{array}{l}\mathrm{L}<3 \\
\mathrm{~L}<3\end{array}$ & $\begin{array}{l}\text { Normal } \\
\text { Normal }\end{array}$ & Operation & oending & \\
\hline J & $40 \mathrm{M}$ & L 3 & Carcinoma & 5 & L 3 & Normal & Operation & oending & \\
\hline K & $28 M$ & $\begin{array}{l}\mathrm{L} 3 \\
\mathrm{~L}<3\end{array}$ & $\begin{array}{l}\text { Normal } \\
\text { Normal }\end{array}$ & & $\begin{array}{l}\mathrm{L}<3 \\
\mathrm{~L}<3\end{array}$ & $\begin{array}{l}\text { Gastritis } \\
\text { Gastritis }\end{array}$ & & & \\
\hline L & $42 M$ & $\begin{array}{l}\text { L } 3 \\
\text { L3 }\end{array}$ & $\begin{array}{l}\text { Normal } \\
\text { Normal }\end{array}$ & & $\begin{array}{l}\text { LNS } \\
\text { LNS }\end{array}$ & $\begin{array}{l}\text { Gastritis } \\
\text { Gastritis }\end{array}$ & & & \\
\hline$M$ & $45 \mathrm{~F}$ & $\begin{array}{l}\text { LNS } \\
\text { LNS } \\
\text { LNS }\end{array}$ & $\begin{array}{l}\text { Gastritis } \\
\text { Gastritis } \\
\text { Gastritis }\end{array}$ & & & & & & \\
\hline$N$ & $39 \mathrm{~F}$ & $\begin{array}{l}\text { LNS } \\
\text { LNS }\end{array}$ & $\begin{array}{l}\text { Normal } \\
\text { Normal }\end{array}$ & & & & & & \\
\hline 0 & $36 \mathrm{M}$ & $\begin{array}{l}\mathrm{L}<5 \\
\mathrm{~L}<5 \\
\mathrm{~L}<5\end{array}$ & $\begin{array}{l}\text { Gastritis } \\
\text { Gastritis } \\
\text { Gastritis }\end{array}$ & Nil & & & & & \\
\hline P & $49 \mathrm{M}$ & LNS & Normal & & & & & & \\
\hline Q & $20 \mathrm{M}$ & L 2 & Normal & & & & & & \\
\hline $\mathrm{R}$ & $18 \mathrm{~F}$ & L 2 & Normal & & & & & & \\
\hline
\end{tabular}

gastroscopy brought forward if appropriate. When pale mucosal abnormalities were detected but biopsy did not show signet ring cell (SRC) carcinoma, re-endoscopy at six months was arranged contingent on the endoscopic appearance. If a patient had ulceration contraindicating pentagastrin use, biopsies were taken of the ulcerated area, treatment instigated, and chromoendoscopy rescheduled.

\section{RESULTS}

A total of 99 surveillance gastroscopies were performed (fig 3). Median surveillance interval was 14 months (range 5-33). A single prolonged surveillance interval of 1823 months occurred in nine patients and an interval of 2733 months in two patients. Surveillance was stopped in two patients: a 51 year old on dialysis for end stage renal failure after two normal chromoendoscopies and a healthy 71 year old who did not wish further endoscopy.

In six procedures chromostaining was not performed because of ulceration (four patients) or detection of a macroscopic lesion (two patients). Paradoxically, the first cancer was detected by standard white light endoscopy. A 38 year old woman (case $S$ ) had an $8 \mathrm{~mm}$ raised nodular lesion on the lesser curve in the mid body. Biopsy showed SRC carcinoma. Chromoendoscopy 14 months prior was normal. She declined surgery and further endoscopy and remains well four years post-diagnosis. One other SRC carcinoma was detected by standard endoscopy in a 49 year old women (case $\mathrm{T}$ ) with a $14 \mathrm{~mm}$ nodular lesion on the anterior wall in the proximal antrum. Her gastrectomy specimen contained 18 foci: the macroscopic lesion (20 $\mathrm{mm}$ ) invaded the muscularis propria (T2); the remaining 17 microscopic foci were confined to the lamina propria.

Of the 93 chromoendoscopies performed, 69 were normal (fig 3). In the remaining 24 chromoendoscopies, 1-6 pale areas were detected, ranging in diameter from 2 to $10 \mathrm{~mm}$. No mucosal abnormality had been visible on standard endoscopy prior to chromo-dye application. In total, 56 pale lesions were detected in these 24 chromoendoscopies in 18 


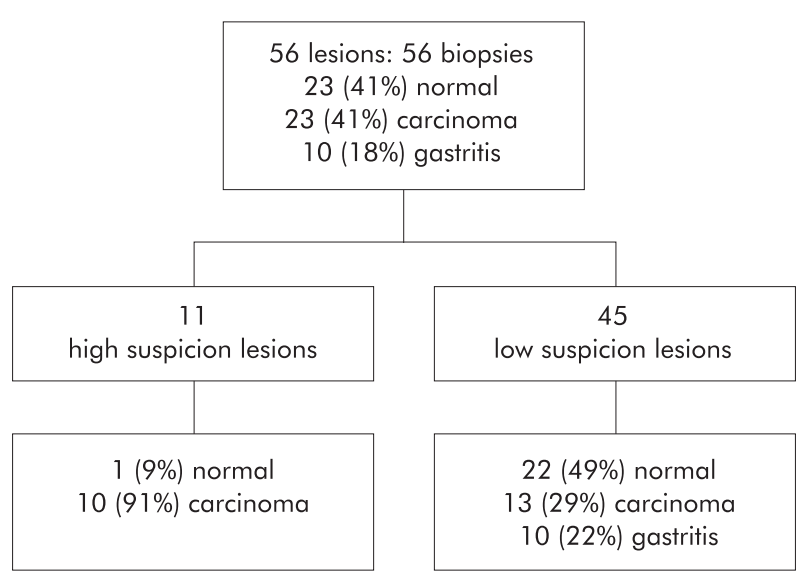

Figure 4 Chromo directed biopsy of 56 pale mucosal lesions.

different patients (table 1, fig 4). One chromo directed biopsy was taken from each pale lesion: 23 (41\%) showed SRC carcinoma (10 patients), 10 (18\%) gastritis (four patients), and $23(41 \%)$ normal mucosa in 10 patients. Biopsy detected carcinoma in 10/11 (91\%) high suspicion pale lesions versus 13/45 (29\%) low suspicion pale lesions.

Only one patient with surveillance detected SRC carcinoma had $H$ pylori infection (case D). Of four patients with gastritis, one (case $\mathrm{M}$ ) had $H$ pylori gastritis; three (cases $\mathrm{K}, \mathrm{M}$, and $\mathrm{O}$ ) had non-specific gastritis. Overall, 7/33 family members had a history of $H$ pylori infection: 6/7 were diagnosed at endoscopy prior to $C D H-1$ mutation testing (1998) and one at their first chromoendoscopy. This is concordant with $H$ pylori serology (available in 30/33 patients). Infected patients were treated with triple therapy.

All 56 pale lesions were detected either in the transitional zone $(30 \%)$ or immediately adjacent to it: distal body $(23 \%)$ or proximal antrum (39\%) (four not stated). Of 23 pale areas which were carcinoma, 11 (48\%) were in the transitional zone, five $(22 \%)$ were in the distal body, and seven $(33 \%)$ were in the proximal antrum $(78 \%$ were found on the greater curve) (table 2).

The first chromo directed biopsy showing SRC carcinoma was in a 38 year old male, case A, with two pale lesions in the proximal antrum on the greater curve. The $10 \mathrm{~mm}$ lesion (carcinoma) was well defined with distinct pallor (fig lA). Fifteen months earlier, one pale area was seen in the same region but the biopsy showed normal mucosa. As with all 10 patients with chromoendoscopy detected SRC carcinoma, case A's total gastrectomy specimen was macroscopically normal with no lymph node metastases. Only 30\% of the mucosal area had pathology mapped (whole antrum mapped) which limits correlation of chromoendoscopic and gastrectomy findings in this first case.

Table 2 Location of pale lesions detected by chromoendoscopic surveillance

\begin{tabular}{lcl}
\hline Location & $\begin{array}{l}\text { Total lesions } \\
(\mathbf{n}=56)\end{array}$ & $\begin{array}{l}\text { Carcinoma } \\
(23 / 56 \text { lesions })\end{array}$ \\
\hline Greater curve & $33(59 \%)$ & $18(78 \%)$ \\
Lesser curve & $9(16 \%)$ & $2(9 \%)$ \\
Anterior wall & $5(9 \%)$ & $3(13 \%)$ \\
Posterior wall & $1(2 \%)$ & - \\
Not stated & $8(14 \%)$ & - \\
\hline
\end{tabular}

Case B, a 28 year old male had a normal chromoendoscopy 19 months prior to two pale areas being detected on the greater curve at the body/antral junction (table 1). The larger pale area was $8 \mathrm{~mm}$ (fig $\mathrm{lB}$ ) and the biopsy showed SRC carcinoma. Correlation of chromoendoscopic and gastrectomy findings showed that of the 214 microscopic foci of intramucosal SRC carcinoma only two were $>4 \mathrm{~mm}$, at $9 \mathrm{~mm}$ and $7 \mathrm{~mm}$, respectively (see gastrectomy map $\mathrm{B}^{13}$ ). The largest focus $(9 \mathrm{~mm})$ was on the greater curve in the proximal antrum, corresponding to the location of the $8 \mathrm{~mm}$ pale area detected by chromoendoscopy.

The third case to show SRC carcinoma in a chromo directed biopsy was a 15 year old (case C) having her second surveillance gastroscopy. Five pale lesions $(3-5 \mathrm{~mm})$ were detected on the greater curve in the proximal antrum (fig IC). Four of five biopsies showed SRC carcinoma. Only seven of the 318 microscopic foci were $>4 \mathrm{~mm}(5-10 \mathrm{~mm})$, all in the same location as the chromoendoscopic pale areas: greater curve, proximal antrum (gastrectomy map $\mathrm{C}^{13}$ ). The mean size of the 311 foci $<4 \mathrm{~mm}$ was $0.4 \mathrm{~mm}$.

Case D, a 34 year old female, had undergone four previous normal chromoendoscopies. She was considering prophylactic gastrectomy and requested a chromoendoscopy after an interval of six months. One subtle $3 \mathrm{~mm}$ low suspicion pale lesion was detected. Biopsy showed SRC carcinoma. The gastrectomy mapping study revealed 111 microscopic foci of SRC carcinoma (gastrectomy map $\mathrm{D}^{13}$ ). All foci were $<2 \mathrm{~mm}$, except for one $4 \mathrm{~mm}$ foci on the greater curve in the proximal antrum/transitional zone-the same location as the chromoendoscopic pale lesion.

During case H's first chromoendoscopy at 18 years of age, two $3 \mathrm{~mm}$ low suspicion areas were detected in the region of the transitional zone but the two biopsies showed normal mucosa. Eighteen months later six pale lesions (3-5 mm) were detected in the proximal antrum/transitional zone area and five of the biopsies detected SRC carcinoma (fig 2A, B). Gastric mapping revealed 238 foci of SRC carcinoma (fig 2C). The six largest foci were 3-4 mm: four were located in the area where pale lesions were detected by chromoendoscopy (three transitional zone; one the distal body/greater curve) and two in the fundus on the greater curve which were not detected by chromoendoscopy.

Case E ( 16 years old, son of case A) had one $3 \mathrm{~mm}$ pale lesion detected on his first chromoendoscopy. The sole biopsy showed SRC carcinoma. Gastric mapping revealed 15 foci of carcinoma. Only two foci were $>1 \mathrm{~mm}$ in size: a $3.3 \mathrm{~mm}$ focus in the transitional zone and a $2.1 \mathrm{~mm}$ focus in the proximal antrum.

Case F (45y female) had 4 previous normal chromoendoscopies before her $5^{\text {th }}$ procedure detected 5 pale lesions $\leqslant 3 \mathrm{~mm}$. All 5 biopsies showed SRC carcinoma. Case G (27 year old female) had two $3 \mathrm{~mm}$ low suspicion areas and one biopsy revealed carcinoma (fig $\mathrm{l} \mathrm{E}, \mathrm{F}$ ). Cases $\mathrm{F}$ and $\mathrm{G}$ have undergone total gastrectomy (macroscopically normal) and gastric mapping is in progress. Chromoendoscopic findings in I and $J$ are listed in table 1 . Their surgery is scheduled.

Annual review of the chromo surveillance programme revealed that eight of the 10 patients with chromo detected carcinoma were diagnosed in the fourth or fifth year (table 3). Each successive year the number of pale areas detected has doubled and the proportion of patients diagnosed with carcinoma per procedure increased (from 6\% to $32 \%$ ).

In summary, in the five years of endoscopic surveillance of $33 \mathrm{CDH}-1$ mutation carriers, SRC carcinoma was diagnosed by chromoendoscopy in 10 patients and by standard white light endoscopy in two patients. Two patients ceased screening and 19 continue surveillance. To our knowledge no advanced gastric cancer has been missed. 


\begin{tabular}{|c|c|c|c|c|}
\hline & Chromoendoscopies & $\begin{array}{l}\text { Pale areas } \\
\text { defected }\end{array}$ & $\begin{array}{l}\text { Carcinoma detected/ } \\
\text { pale areas }(\%)\end{array}$ & $\begin{array}{l}\text { Patients diagnosed with } \\
\text { carcinoma/chromoendoscopies }(\%)\end{array}$ \\
\hline Year 1 & 19 & 1 & $0 / 1(0 \%)$ & $0 / 19(0 \%)$ \\
\hline Year 2 & 18 & 2 & $1 / 2(50 \%)$ & $1 / 18(6 \%)$ \\
\hline Year 3 & 18 & 4 & $1 / 4(25 \%)$ & $1 / 18(6 \%)$ \\
\hline Year 4 & 19 & 18 & $5 / 18(28 \%)$ & $2 / 19(11 \%)$ \\
\hline Year 5 & 19 & 31 & $16 / 31(52 \%)$ & $6 / 19$ (32\%) \\
\hline Total & 93 & 56 & $23 / 56(41 \%)$ & 10/93 (11\%) \\
\hline
\end{tabular}

\section{DISCUSSION}

The management of patients carrying a germline $C D H-1$ mutation is difficult. The situation is complicated by the young age at which individuals may develop carcinoma and the incomplete penetrance of the mutation $(70 \%)$. While prophylactic total gastrectomy does remove the risk of gastric cancer, it is associated with significant morbidity and mortality. ${ }^{6}$ Consequently, it is not an acceptable option for all. Our initial experience with congo red-methylene blue chromoendoscopy in $33 \mathrm{CDH}-1$ mutation carriers who did not wish to undergo prophylactic gastrectomy resulted in the detection of 23 early SRC carcinoma foci (in 10 patients) which were not visible with standard white light gastroscopy. The chromoendoscopic findings in these 10 patients were confirmed at subsequent total gastrectomy.

Evolution in our understanding of the early pathology in HDGC, the observed gene penetrance, and the limitations of standard gastroscopy as a surveillance tool in HDGC have resulted in two different management strategies for this new familial cancer syndrome- "surveillance gastroscopy" and "prophylactic gastrectomy". Ten prophylactic gastrectomies in North American HDGC kindred ${ }^{4}$ and a New Zealand series of six gastrectomies from three kindred (including family A $)^{14}$ have all exhibited microscopic foci of intramucosal SRC carcinoma. All foci were confined to the superficial lamina propria and all gastrectomies had no lymph node metastases. The foci of carcinoma were not visible using white light gastroscopy in the North American cases (all foci were $<8 \mathrm{~mm}$ ) or in five of the six patients in the New Zealand gastrectomy series. These 15 cases illustrate the limitations of standard endoscopy in detecting early HDGC.

Due to concern over the sensitivity of methods for early detection in HDGC, prophylactic gastrectomy has been advocated for prevention. ${ }^{6}$ Guidelines on surveillance gastroscopy in $C D H-1$ mutation carriers declining prophylactic gastrectomy recommend careful examination, with multiple biopsies of even the subtlest gastric lesions. ${ }^{17}$ Multiple random gastric biopsies taken during endoscopic screening in the two North American HDGC series failed to detect carcinoma. ${ }^{45}$

Our experience with congo red-methylene blue chromoendoscopy suggests this is an improvement over standard gastroscopy, facilitating detection of 56 pale lesions of which $23(41 \%)$ were SRC carcinoma (91\% of high suspicion lesions and $29 \%$ of low suspicion lesions). These pale lesions were usually 3-5 mm, allowing only one accurate chromo directed biopsy. We elected not to perform "control random biopsies" prior to chromo dye application due to concern that bleeding from 20-30 biopsy sites would compromise the detection of pale areas and in the knowledge that previous undirected biopsies had failed to detect carcinoma in other series. ${ }^{45}$

Correlation of the gastrectomy mapping study ${ }^{14}$ with chromoendoscopy findings demonstrates that the pale lesions identified at chromoendoscopy appear to correspond to the larger foci of $4-10 \mathrm{~mm}$ which are located in the distal stomach, predominantly the body-antral transitional zone. As congo red allows determination of the parietal cell/acid secreting mucosal area, ${ }^{18}$ the region of the transitional zone can be approximated. Repeat preoperative chromoendoscopy with ink tattooing of pale areas would permit precise correlation of chromoendoscopic findings with foci location in the gastrectomies. In light of the pathology mapping study and given it would require an additional procedure for patients, this has not been performed. To date, mapping has been completed in six members of family A. In addition to the transitional zone predominance previously described, ${ }^{14}$ there is relative "antral sparing" (particularly of the distal antrum): patients either have no antral foci (cases $\mathrm{E}, \mathrm{H}$, and $\mathrm{T}$ ) or a small proportion of total foci are antral (case B $7 \%$, case C 9\%, and case D 18\%).

Facilitated endoscopic diagnosis of gastric cancer using the congo red-methylene blue test was first described by Tatsuta and colleagues. ${ }^{11}$ Normal stomach mucosa does not stain with methylene blue but is taken up by intestinalised gastric cells, indicating intestinal metaplasia. ${ }^{13}$ Congo red changes from red to blue/black at $\mathrm{pH}<3^{19}$ and has been used to determine the extent of vagotomy, detect duodenal ectopic gastric tissue, study acid secreting mucosa, and historically as an intravenous test for amyloidosis. ${ }^{9} 18$ Congo red was initially investigated in preoperative gastroscopy as a means of defining the extent of gastric malignancy. In a series of 35 patients it increased the diagnostic accuracy of cancer extent from $40 \%$ by routine endoscopy to $85.7 \% .^{20}$ Another study revealed an increase in the diagnostic rate of multiple early gastric cancers from $28 \%$ by routine endoscopy to $89 \%$ with the methylene blue-congo red test. ${ }^{21}$ It is postulated that an area of gastric carcinoma will not contain parietal cells so there is no acid secretion and the carcinoma is thus seen as a pale area surrounded by the blue-black colour conversion of congo red by normal acid secreting mucosa.

Congo red use in endoscopy has previously been reported to be non-toxic, devoid of side effects, and well tolerated. ${ }^{92}$ In 2002, our new supply arrived labelled as a potential carcinogen with possible embryotoxic effects. ${ }^{23}$ Congo red has two identical sulphated molecules attached via azo bonds to a central benzidine molecule. In murine studies, offspring from pregnant mice given oral congo red were subfertile due to gonadal atrophy. ${ }^{24}$ Data on mutagenicity comes from murine skin exposure tests looking at DNA adduct formation ${ }^{25}$ and rat hepatocyte DNA repair assays. ${ }^{26}$ Azo dyes based on benzidine have long been implicated in the increased incidence of testicular cancer in textile workers. ${ }^{27}$ Studies in rats show that reductive cleavage of azo bonds can occur by intestinal bacteria, with consequent benzidine absorption. ${ }^{28}$ Safety protocols should clearly be followed by all staff handling congo red. However, it is difficult to assess the implications of this limited murine data for patients having once yearly chromoendoscopy. We have reviewed our consent policy and are considering pre-procedure pregnancy testing. It is our standard practice to suction away all residual dyes. 
We continue performing chromoendoscopy because the risks from congo red exposure need to be balanced against the benefit of cancer detection.

The 56 pale lesions detected using chromoendoscopy in our HDGC stomachs were not surrounded by a blue/black stain, as described in the original paper. ${ }^{11}$ This may reflect the fact that we not only aspirate residual dye, as described by the Japanese, but also thoroughly irrigate with water after application of the dyes to aid visualisation of the mucosa. However, the characteristics of the high risk pale lesions (fig 1A, B, C) which are well defined white areas surrounded by red tinged mucosa, and their location (transitional zone/ proximal antrum-parietal cells fade out through the transitional zone being absent in the antrum), lead us to speculate that mechanisms other than acid secretion might be involved. Possibilities include: (1) the epithelium overlying the carcinoma foci may function differently from adjacent normal epithelium (for example, mucin expression) which renders it congo phobic; (2) the presence of SRC carcinoma may distort the three dimensional pit pattern and/ or compress gland and pit lumens preventing congo red staining; (3) the use of the mucolytic $\mathrm{N}$-acetylcysteine (Parlovex) instead of the proteinase used in the Japanese series may be relevant; and (4) there is an interaction between congo red and methylene blue. With respect to the latter, methylene blue uptake was minimal in these patients and given that the intestinal metaplasia-dysplasia-carcinoma pathway is not considered relevant in diffuse-type carcinoma, we believe methylene blue does not contribute to early gastric cancer detection in HDGC. Based on our experience we are currently considering the merits of changing the protocol order to congo red, pentagastrin, and lastly methylene blue, with careful inspection at each interval to determine when the pale areas become evident.

The number of pale areas detected chromoendoscopically approximately doubled each year of surveillance despite no change in procedures/year, and 8/10 patients were diagnosed in the fourth or fifth year of surveillance. Prima facie this could be interpreted as a learning curve effect in relation to detection or biopsy accuracy. However, it is not possible to draw this conclusion without formal interobserver studies. Of note, the diagnosis of carcinoma was made in the first chromoendoscopy for two of these eight patients and three others each had four previous normal chromoendoscopies (table 1). The remaining three patients had low suspicion lesions detected in the same region of their stomach the previous year with normal biopsy results. One endoscopist (DS) performed all endoscopies with many procedures observed by the other authors. While the technique is straightforward, interpretation of findings, particularly detection of smaller pale areas $\leqslant 3 \mathrm{~mm}$, seemed to improve with experience.

The HDGC patients in the three gastrectomy series to date have a combined average age of 32 years and no stomach has been reported without microscopic foci. ${ }^{4}{ }^{14}$ Penetrance data for advanced cancer risk in HDGC shows that at 40 years the cumulative risk of stomach cancer is $9 \%$ (95\% confidence interval 3-34) in men and $21 \%(11-46 \%)$ in women. ${ }^{29}$ One study of the natural history of early sporadic gastric cancer showed a cumulative five year risk of progression to advanced gastric cancer of $63 \% .^{30}$ Even allowing for a 510 year time lag for cancer to progress from these early HDGC lesions, penetrance for advanced disease at 50 years is still only $21 \%$ in men and $46 \%$ in women. ${ }^{29}$ The above observation of $100 \%$ penetrance for microscopic foci suggests that these early SRC foci have an initial indolent course which may last many years.

If, after more gastrectomies have been performed, it appears that all patients have early disease by the second to third decade or earlier, the concepts of prophylactic gastrectomy and surveillance gastroscopy to detect disease will by definition be incorrect. The assumption will then be that very early disease will be present in all adult $C D H-1$ mutation carriers and the aim of endoscopic surveillance will be to detect disease progression.

Theoretically, if foci size parallels disease progression, then the larger foci of 4-9 $\mathrm{mm}$ would be more likely to progress and the diagnostic limitations of chromoendoscopy would be advantageous in selecting patients for timely gastrectomy. However, the infallibility of "endoscopic surveillance for disease progression" is reliant on finding a detectable marker that correlates predictably with cancer progression. Only with such a marker will $C D H-1$ mutation carriers requiring gastrectomy be able to be selected with confidence. Our initial experience shows that chromoendoscopy is better than standard endoscopy for surveillance of E-cadherin mutation carriers. If these findings are validated in other HDGC kindred, it will offer an alternative to prophylactic gastrectomy.

\section{ACKNOWLEDGEMENTS}

We thank the staff at Kimihauora Health Centre; the endoscopy nurses, Day Stay Unit, Tauranga Hospital; Dave Wilson, Pharmacist, Tauranga Hospital; and Michael Beasley, Medical Toxicologist, National Poisons Centre, Dunedin, New Zealand.

\section{Authors' affiliations}

D Shaw*, A Framp, Department of Medicine, Tauranga Hospital, Tauranga, New Zealand

V Blair*, I Martin, Department of Surgery, University of Auckland, Middlemore Hospital, Auckland, New Zealand

P Harawira, M McLeod, Kimihauora Health Centre, Mount Maunganui, New Zealand

P Guilford, Cancer Genetics Laboratory, Department of Biochemistry, University of Otago, Dunedin, New Zealand

S Parry, Department of Gastroenterology, Middlemore Hospital, Auckland, New Zealand

A Charlton, Department of Pathology, Middlemore Hospital, Auckland, New Zealand

*D Shaw and $V$ Blair are joint first authors.

Conflict of interest: None declared.

\section{REFERENCES}

1 Jones E. Familial gastric cancer. N Z Med J 1964;63:287-96.

2 Guilford P, Hopkins J, Harrawa, et al. E-cadherin germline mutations in familial gastric cancer. Nature 1998;392:402-5.

3 Guilford P, Hopkins J, Grady W, et al. E-cadherin germline mutations define an inherited cancer syndrome dominated by diffuse gastric cancer. Hum Mutat 1999; 14:249-55.

4 Chun YS, Lindor NM, Smyrk TC, et al. Germline E-cadherin mutations: Is prophylactic gastrectomy indicated? Cancer 2001;92:181-7.

5 Huntsman DG, Carneiro F, Lewis FR, et al. Early gastric cancer in young asymptomatic carriers of germline E-cadherin mutations. N Engl J Med 2001;344:1904-9.

6 Lewis FR, Mellinger JD, Hayashi A, et al. Prophylactic total gastrectomy for familial cancer. Surgery 2001;130:612-19.

7 Liedman B. Symptoms after total gastrectomy on food intake, body composition, bone metabolism and quality of life in gastric cancer patients - is reconstrustion of a reservoir worthwhile? Nutrition 1999;15:677-82.

8 Dacosta RS WB, Marcon NE. New optical technologies for earlier endoscopic diagnosis of premalignant gastrointestinal lesions. J Gastroenterol Hepatol 2002;17:S85-104.

9 Fennerty M. Tissue staining. Gastroenterol Clin North Am 1994;4:297-331.

10 Yamashina M. A variant of early gastric carcinoma: histologic and histochemical studies of early signet ring cell carcinomas discovered beneath preserved surface epithelium. Cancer 1986;58:1333-9.

11 Tatsuta M, Okuda S, Tamura H, et al. Endoscopic diagnosis of early gastric cancer by the endoscopic congo red-methylene blue test. Cancer 1982;50:2956-60.

12 Tatsuta M, Okuda S, Taniguchi H, et al. Gross and histological types of early gastric carcinomas in relation to the acid-secreting area. Cancer 1979;47:317.

13 Ida K HY, Kawai K. In vivo staining of gastric mucosa. Endoscopy 1975;7:18-24. 
14 Charlton A, Blair V, Shaw D et al. Hereditary diffuse gastric cancer: predominance of multiple foci of signet ring cell carcinoma in distal stomach and transitional zone. Gut 2004;53:814-20.

15 Fennerty M, Sampliner R, McGee D, et al. Intestinal metaplasia of the stomach: identification by a selective mucosal staining technique. Gastrointest Endosc 1992;38:696-98.

16 Japanese Research Society for Gastric Cancer. Japanese Classification of Gastric Carcinoma. Tokyo: Kanehara and Co. Ltd, 1995.

17 Caldas C, Carneiro F, Lynch HT, et al. Familial gastric cancer: overview and guidelines for management. J Med Genet 1999:36:873-80.

18 Toth E, Sjolund K, Thorsson O, et al. Evaluation of gastric acid secretion at endoscopy with a modified congo red test. Gastrointest Endosc 2002;56:254-9.

19 Steensma D. "Congo" Red: Out of Africa? Arch Pathol Lab Med $2001 ; 125: 250-2$

20 Tatsuta M, Okuda S, Tamura H, et al. Endoscopic determination of the extent of early ulcerated gastric cancer by the congo red test. Endoscopy 1982;14:41-4

21 lishi $\mathrm{H}$, Tatsuta $M$, Okuda $\mathrm{S}$. Diagnosis of simultaneous multiple gastric cancers by the endoscopic congo red-methylene blue test. Endoscopy 1988;20:78-82.

22 Acar 0 , Schwizer O, Hauri D. The use of congo red mapping and marking for delineating the antral-corpus boundary during gastric bladder augmentation and replacement. Br J Urol 1999;84:725-26.
23 MerckChemicalDatabase. Safety data sheet: congo red, catalouge No 105233. www.chemdat.de/mda/index.html.

24 Gray L, Ostby J, Kavlock R, et al. Gonadal effects of fetal exposure to the azo dye congo red in mice: infertility in female but not male offspring. Fundam Appl Toxicol 1992;19:411-22.

25 Reddy M, Gupta R, Randerath E, et al. ${ }^{32}$ P-Postlabeling test for covalent DNA binding of chemicals in vivo: application to a variety of aromatic carcinogens and methylating agents. Carcinogenesis 1984;5:231-43.

26 Kornbrust D, Barfknecht T. Comparison of 7 azo dyes and their azo reduction products in the rat and hamster hepatocyte primary culture/DNA-repair assays. Mutat Res 1984;136:255-66.

27 Zenser T, Lakshmi V, Davis B. N-Glucuronidation of benzidine and its metabolites: role in bladder cancer. Drug Metab Dispos 1998;26:856-9.

28 Bos R, Koopman J, Theuws J, et al. The essential role of the intestinal flora in the toxification of orally administered benzidine-based dyes: internal exposure of rats to benzidine after intestinal azo reduction. Mutat Res 1987; 181:327

29 Pharoah P, Guilford P, Caldas C, et al. Incidence of gastric cancer and breast cancer in $\mathrm{CDHl}$ (E-cadherin) mutation carriers from hereditary diffuse gastric cancer families. Gastroenterology 2001;121:1348-53.

30 Tsukuma H, Oshima A, Narahara H, et al. Natural history of early gastic cancer: a non-concurrent long term followup study. Gut 2000;47:618-21.

\section{EDITOR'S QUIZ: GI SNAPSHOT}

\section{Giant gastric ulcer: an endoscopic roller coaster}

\section{Clinical presentation}

A 39 year old male who was a chronic user of non-steroidal analgesics, alcohol, and tobacco presented with recurrent haematemesis. He was haemodynamically stable but pale and tender in the epigastrium. No other abnormalities were noted.

Haematological evaluation confirmed iron deficiency anaemia. Total protein and albumin were $47 \mathrm{~g} / \mathrm{dl}$ and $21 \mathrm{~g} / \mathrm{dl}$, respectively. Gastroscopy and barium meal findings are shown in fig $\mathrm{lA}$ and $\mathrm{IB}$, respectively.

\section{Question}

What is the diagnosis and how does it usually present?

See page 509 for answer

This case is submitted by:

A O Laosebikan, V Govindasamy, G Chinnery, F Ghimenton Department of Surgery, Greys Hospital, Pietermaritzburg, South Africa S R Thomson

Department of Surgery, Nelson R Mandela School of Medicine, University of KwaZulu-Natal, Durban, South Africa

Correspondence to: Mr A O Laosebikan, Department of Surgery, Greys Hospital, Private Bag X9001, Pietemaritzburg, 3200, KwaZulu-natal, South Africa; maharajk@dohgreys.kzntl.gov.za

doi: $10.1136 /$ gut.2004.048579
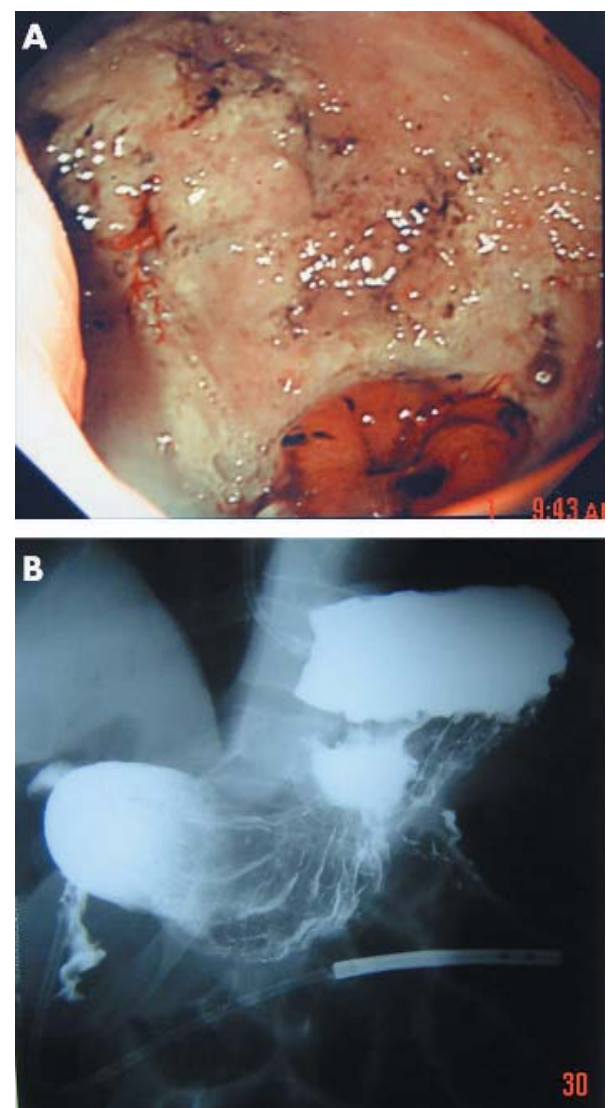

Figure 1 Gastroscopy (A) and barium meal (B) findings in the patient. 